\title{
Anabases
}

ANABASES Traditions et réceptions de l'Antiquité

$8 \mid 2008$

Varia

\section{François HARTOG, Vidal-Naquet, historien en personne. L'homme-mémoire et le moment-mémoire}

\section{Catherine Valenti}

\section{(2) OpenEdition}

\section{Journals}

Édition électronique

URL : http://journals.openedition.org/anabases/254

DOI : 10.4000/anabases.254

ISSN : 2256-9421

\section{Éditeur}

E.R.A.S.M.E.

\section{Édition imprimée}

Date de publication : 1 octobre 2008

Pagination : 291-293

ISSN : 1774-4296

\section{Référence électronique}

Catherine Valenti, « François HARTOG, Vidal-Naquet, historien en personne. L'homme-mémoire et le momentmémoire », Anabases [En ligne], 8 | 2008, mis en ligne le 01 juillet 2011, consulté le 22 septembre 2020. URL : http://journals.openedition.org/anabases/254 ; DOI : https://doi.org/10.4000/anabases.254

Ce document a été généré automatiquement le 22 septembre 2020.

(c) Anabases 


\title{
François HARTOG, Vidal-Naquet, historien en personne. L'homme- mémoire et le moment-mémoire
}

\author{
Catherine Valenti
}

\section{RÉFÉRENCE}

François HARTOG, Vidal-Naquet, historien en personne. L'homme-mémoire et le momentmémoire, Paris, La Découverte, 2007, 142 p.

12 euros / ISBN 978-2-7071-5319-7.

1 Répondant par avance à d'éventuelles critiques, dans l'introduction du court ouvrage qu'il consacre à Pierre Vidal-Naquet, François Hartog se défend de vouloir faire la biographie de celui qui, à travers les deux volumes de ses Mémoires parus en 1995 et 1998, avait déjà longuement réfléchi lui-même sur son parcours et son engagement d'historien. Hartog annonce en réalité un projet autrement ambitieux : il ne souhaite rien de moins que livrer une interrogation sur l'historien Vidal-Naquet et, à travers lui, sur l'histoire elle-même.

2 À travers trois chapitres chronologiques et un quatrième plus thématique, l'auteur s'attache ainsi à replacer l'œuvre de Pierre Vidal-Naquet dans les contextes historiques et historiographiques successifs de la deuxième moitié du $\mathrm{xx}^{\mathrm{e}}$ siècle: à travers le parcours de Vidal-Naquet, c'est en effet plus d'un demi-siècle d'histoire mais aussi d'historiographie françaises qu'il est possible d'appréhender.

Le premier chapitre traite du parcours universitaire et du choix de la Grèce ancienne, Platon étant d'abord conçu comme un moyen d'échapper aux emballements politiques et à la «tyrannie de l'immédiat ». Ce choix apparaît pour le moins paradoxal chez un homme qui ne cessera par la suite d'affirmer que toute interrogation sur l'histoire a nécessairement des résonances contemporaines, et que l'historien n'interroge le passé qu'en fonction de ses préoccupations du moment : Vidal-Naquet ne s'engage-t-il pas dès 
1958 dans la plus brûlante des actualités d'alors, le conflit algérien, à travers ce qui sera son affaire Dreyfus, l'affaire Audin, du nom de ce jeune universitaire communiste arrêté par des parachutistes français pendant la bataille d'Alger et disparu sans laisser de traces?

4 Comme le rappelle le deuxième chapitre, les années 1960 constituent pour Pierre VidalNaquet le point de départ d'activités multiples, voire d'un activisme qui ne se démentira plus jusqu'à sa mort. Si la Grèce et le monde antique sont évidemment toujours présents, ils le sont tout autant comme objets d'études à part entière que comme un biais pour retrouver les interrogations les plus contemporaines : ainsi un travail sur La Guerre des Juifs de Flavius Josèphe, que l'éditeur Jérôme Lindon lui a demandé de préfacer, est-il l'occasion pour Vidal-Naquet d'aborder la question juive au $\mathrm{xx}^{\mathrm{e}}$ siècle, de faire le lien entre passé et présent, à travers notamment l'épisode de Massada, devenu symbole de la résistance à l'envahisseur et métaphore du sionisme. Est-ce un hasard si, aussitôt après Flavius Josèphe, Vidal-Naquet se lance dans le combat contre le négationnisme? Il explique lui-même dans ses Mémoires comment, autour du destin juif, « son propre destin bascula ».

5 Le troisième chapitre s'articule autour de "l'homme-mémoire» et du «momentmémoire » mentionnés dans le sous-titre de l'ouvrage. À partir des années 1970-80 s'enclenche en effet en Occident une poussée mémorielle dont les effets se font encore sentir aujourd'hui, et à laquelle Pierre Vidal-Naquet ne pouvait pas rester indifférent. Dans les Mémoires, dont la rédaction occupe la dernière période de sa vie, l'historien de la Grèce antique parle de lui en tant qu'historien, le "sujet " du récit se regardant simultanément comme son «objet ». En ce sens, les Mémoires de Pierre Vidal-Naquet, dans lesquels il essaie d'intégrer sa propre mémoire à l'histoire, ne sont rien d'autre qu'une continuation de l'histoire par d'autres moyens.

6 De façon moins convaincante, le quatrième chapitre se propose de revenir sur l'ensemble du demi-siècle évoqué dans les trois précédentes parties, non plus en éclairant les choix de l'historien en rapport avec les contextes successifs, mais en allant au contraire de l'historien au contexte, c'est-à-dire en s'interrogeant sur la représentativité du parcours de Vidal-Naquet. On ne voit guère ce qu'apporte le changement de perspective, et les compléments d'information et de réflexion - sur les remises en cause du récit historique ou le problème de la mémoire notamment auraient aisément trouvé leur place dans les chapitres antérieurs.

7 Au final se détache la figure d'un polyhistor - à la fois celui qui « traite en historien des dossiers variés qui deviennent autant d'“affaires" ", mais aussi celui qui s'emploie à appréhender un texte dans toutes ses dimensions - sans toutefois que François Hartog apporte des éléments qui soient tous entièrement neufs au portrait de cet « historien en personne » ou aux débats historiques et historiographiques qui ont servi de toile de fond à son engagement. 


\section{AUTEURS}

\section{CATHERINE VALENTI}

Université de Toulouse II

cathy.valenti@aliceadsl.fr 